\title{
Investigation of hydraulic imbalance for converting existing boiler based buildings to low temperature district heating
}

\author{
Asad Ashfaq ${ }^{\mathrm{a}, *}$, Anton Ianakieva \\ ${ }^{a}$ Department of Civil Engineering, Nottingham Trent University, NG1 $4 F Q$ Nottingham, United Kingdom
}

\begin{abstract}
The hydraulic balance of heating network is considered as a pre-condition for the implementation of low temperature district heating (LTDH). Its imbalance result into high energy consumption and heat-losses in the network. In this study, a novel hydraulic model is presented which investigates hydraulic imbalance in the LTDH network, using real weather and hourly monitored operational heating data from an existing boiler based building. Analysis of delta $t$ in space-heating system shows that the delta $t$ is maximum when the outside air temperature is lowest and it decreases with increase in outside air temperature. Furthermore, the hydraulic imbalance is analysed for four different control scenarios with the aim to find an optimum scenario with minimum pumping power, energy consumption and heat-losses in the LTDH network. Results show that the hydraulic imbalance is due to the absence of flow-limiters and balancing valves on the return pipe and thermostatic radiator valves (TRVs) alone are unable to maintain hydraulic balance in the spaceheating system of buildings. Moreover, the control scenario with variable flow-rate and fixed supply water temperature from the sub-station is found to be optimum. Compared to the constant flow-rate scenario, the pumping power, energy consumption and heat-losses in the LTDH network are reduced by approximately $2 \%, 63 \%$ and $14 \%$, respectively.
\end{abstract}

Keywords: low temperature district heating, hydraulic imbalance, renewable energy, retrofitting of buildings, delta t, radiator connections

\section{Introduction}

With recent increasing environmental and energy efficiency concerns, maximising the efficiency of heating sector is thought as a key factor to foster future fossil-free energy policy. Recently, it is calculated that the heating sector represents $79 \%$ (192.5 Mtoe) of the final energy consumption in EU and district heating is 5 considered as central towards sustainable energy system development [1, 2]. The United Kingdom represents second highest heat demand among other European countries [3]. The space heat and hot water is commonly supplied by individual gas-boiler in buildings and the share of district heating is currently less than $2 \%$ which

\footnotetext{
${ }^{*}$ Corresponding author

Email address: asad_ashfaq2000@yahoo.com (Asad Ashfaq )

${ }^{1}$ Department of Civil Engineering, Nottingham Trent University, NG1 4FQ Nottingham, United Kingdom
} 
can easily be increased up to $14 \%$ [4, especially in the central and south-eastern regions of the UK. The geographical distribution of heat demand in the UK is shown in Fig.1.

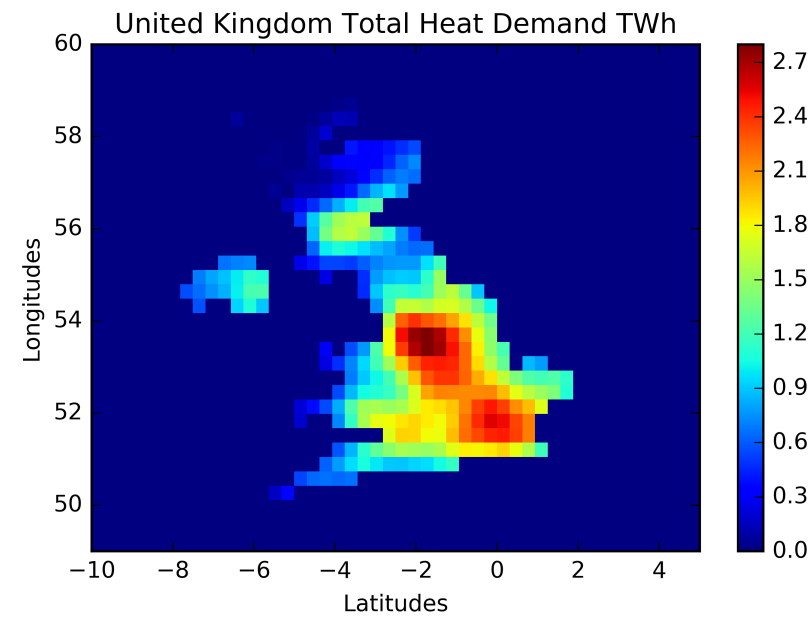

Figure 1: Geographical distribution of heat demand in United Kingdom at spatial resolution of $40 \mathrm{x} 40 \mathrm{~km}^{2}$ for the year (2011), taken from Ref. [5]. This illustrates that, the central and south-eastern regions of the UK have higher heat demand compared to other regions. This elaborates the significance of district heating in Nottingham and the case study used in this paper. (For interpretation of the references to colour in this figure legend, the reader is referred to the web version of this article).

The historical origin of district heating can be traced back to east-European countries and Russia (the former soviet union), where $1^{\text {st }}$ generation district heating was used as the communal heating source for buildings in densely populated areas. However, it did not prove to be successful due to the inefficient system and lack of control [6]. The same district heating technology and methodology was adopted by Scandinavian countries and district heating technology experienced rapid modernisation with higher efficient systems [6, 7].

15 The district heating has four generations and the major difference among these $1^{\text {st }}$ to $4^{\text {th }}$ generation is reduction in the supply water temperature from $\geq 200^{\circ} \mathrm{C}$ to $<60^{\circ} \mathrm{C}$ [7]. The $4^{\text {th }}$ generation district heating is also known as low temperature district heating (LTDH). It's main characteristic is to decrease supply and return water temperature of the district heating to $60^{\circ} \mathrm{C}$ and $30^{\circ} \mathrm{C}$, respectively. This makes the integration of renewable energy sources possible into the heat network.

Although, several studies have demonstrated the benefits of district heating and low temperature district heating, it still faces serious challenges which act as a barrier towards the transition to LTDH [8]. Several authors have identified these challenges as, maintaining high difference between the supply and return water temperature i.e delta $\mathrm{t}(\Delta \mathrm{t})$, hydraulic imbalance [9], optimisation of the demand driven system [10] and the legionella growth [11, 12. Ostergaard et al. [13] and Tunzi et al. [14] have discussed the importance of thermostatic radiator valves $(\mathrm{TRVs})$ in maintaining high $\Delta \mathrm{t}$ in existing hydronic heating networks, and highlighted the problem of over-sized designing of space-heating system in existing buildings. Zhang et al. [15. 16, 17] have identified hydraulic imbalance as the main reason for over-heating in buildings and heatlosses in the Chinese district heating network. Yan et al. [18] evaluated the hydraulic performance of district 
heating network with several independent variable speed pumps. Wang et al. [19] presented a hydraulic model for optimising the district heating network economically.

The novelty of this study, compared to earlier studies, is to present the significance of using hourly monitored operational data from existing space-heating system for hydraulic imbalance investigation in the LTDH network. The LTDH is the most efficient district heating technology and requires precise designing. In this paper, a model has been developed in Python programming language to analyse the hydraulic imbalance

35 in LTDH networks. The hydraulic imbalance problem leads to low $\Delta \mathrm{t}$, high supply water temperature, flow-rate, pumping energy, energy and heat-loss across the heating network. Moreover, multiple years of monitored weather data is used to calculate energy savings from the renovation of buildings. This weather data is significant to this research as heat losses in the district heating network and space heat demand inside the apartment depends on it. These monitored weather data and operational data from an existing boiler based building before the conversion to LTDH are used for the analysis and results are compared for different operational scenarios.

The flow of this study is as follow: firstly the methodology for heat demand and hydraulic modelling is discussed in Section 2, then the LTDH intervention in Nottingham is presented as a case study in Section 3 Subsequently, the real hourly monitored weather data and operational space-heating system data of an existing boiler based building are discussed in Sections 4.1 and 4.3.1, respectively. Later, the hydraulic performance of LTDH network is analysed by assuming four different operational scenarios in Section 4.3 Finally, results for the optimum scenario, along with recommendations for the future LTDH network are given in Section 5 .

\section{Methods and modelling}

The hydraulic performance modelling of the heating network is divided into two parts namely, heat demand modelling and hydraulic modelling. The heat demand modelling is performed by modelling the building in IDA-ICE software and calculations are performed using real monitored weather data. The hydraulic performance is evaluated using a mathematical hydraulic model developed in Python programming language. This provides necessary customisation and flexibility in implementing various thermal models for the analysis.

\subsection{Heat demand modelling}

The building is modelled in IDA-ICE 4.6.2 for heat-load estimation. IDA-ICE is a dynamic multi-zone simulation software commonly used by researchers and consultants [20]. This software is validated in-conformance with the standard DS/EN 15265 [21, 22] and uses an advanced algorithm for calculating energy performance of buildings using dynamic methods. The building geometry is first modelled using it's parameters such as, orientation, exposed perimeters and U-values. Then, the design conditions are set according to the standard [23] with the outdoor temperature of $-8^{\circ} \mathrm{C}$ for extreme events [24]. Subsequently, the detailed dynamic simulations are performed using weather data for Nottingham. 
The heat demand depends upon outside weather conditions, therefore three years (2014-2016) of meteorological data is taken from weather station located in proximity to the case-study building used in this research at $53^{\circ} 3^{\prime} 41.62^{\prime \prime} \mathrm{N}, 0^{\circ} 57^{\prime} 49.75^{\prime \prime} \mathrm{W}$. This meteorological data having temporal resolution of 15 minutes is first averaged into hourly mean values and then, converted into EnergyPlus format (.epw) weather file. This weather file is imported into IDA-ICE for heat demand estimation.

The thermal characteristics of the building are calculated using weather data from .epw climate file to maintain the indoor air temperature of $19^{\circ} \mathrm{C}$ in every zone. The natural ventilation is taken as $0.94 \mathrm{ac} / \mathrm{hr}$. This is standard minimum required ventilation in domestic buildings and in-accordance to the CIBSE Building Code [25]. The occupants' activity and house-hold equipment utilisation are taken on weekly schedules and the heat gains are assumed as for the domestic building conditions i.e. 0.81 and $1.55 \mathrm{~W} / \mathrm{m}^{2}$, respectively 14.

\subsection{Hydraulic modelling}

The hydraulic model of district heating network is developed with few following assumptions. This is to reduce the computational time without significant loss of accuracy.

- The water is in-compressible.

- There is no leakage in pipes.

- The supply water and return water pipelines are symmetrical.

The first step in hydraulic modelling is calculating required flow-rate, flow velocity in district heating pipes. This is done by calculating mass flow-rate $(m)$ in each district heating pipe from the Eq. (1). The density $(\rho)$ and specific heat $\left(C_{p}\right)$ of water decreases with increase in water temperature. These are calculated using Eqs.22) and (3) to get accurate results.

$$
\begin{gathered}
m=\frac{Q}{C_{p}\left(T_{s}-T_{r}\right)} \\
\rho=1000.6-\left(0.0128 * T_{\text {water }}^{1.76}\right) \\
C_{p}=4209.1-\left(132.8 * 10^{-2} * T_{\text {water }}\right)+\left(143.2 * 10^{-4} * T_{\text {water }}^{2}\right)
\end{gathered}
$$

where $Q$ is the heat load, $T_{s}$ and $T_{r}$ are the supply and return water temperature in each pipe, respectively. The flow-velocity in each pipe is calculated from mass flow-rate as the diameter of pipes is already known. However, the maximum allowable flow-velocity is always kept less than or equal to $2 \mathrm{~m} / \mathrm{s}$, as recommended in the design code standard [25]. The flow-rate $(q)$ is limited according to the design values by modelling 
control valves in the heating network. The control valves regulate flow across the valve to required value by changing its opening. The flow-rate through the control valve for a given pressure drop $(\Delta \mathrm{P})$ is calculated as

$$
q=K_{v} \sqrt{\Delta P_{v}}
$$

$K_{v}$ is the flow capacity of valve and $\Delta P_{v}$ (bar) is the controlled differential pressure across the valve. The head-loss $\left(\Delta h_{f}\right)$ in pipes is estimated by Darcy equation [26].

$$
\Delta h_{f}=\frac{8 \cdot f \cdot l \cdot q^{2}}{\pi^{2} \cdot d^{5} \cdot g}
$$

$l$ is the length of pipe, $d$ is the diameter of the pipe and $f$ is the friction factor estimated by Swamee-Jain equation [27].

$$
f=\frac{0.25}{\left[\log \frac{e / d}{3.7}+\frac{5.74}{R e^{0.9}}\right]^{2}}
$$

where $e$ is the roughness of inner pipe surface. Re is the Reynold number of flow in the pipe. The flow-rate in each pipe is calculated using principles of fluid dynamics from Ref. [27].

\subsubsection{Energy consumption calculation}

The pumping power $\left(P_{a}\right)$ and electricity consumption $(E)$ of the heating network are calculated using Eqs. (7) and (8).

$$
\begin{gathered}
P_{a}=\frac{\rho \cdot g \cdot \Delta h_{f} \cdot q}{\eta} \\
E=\frac{S * P_{a}}{\eta_{m}}
\end{gathered}
$$

where $P_{a}$ is the shaft pumping power, $g$ is the gravitational constant, $S$ is the security factor taken as 1.1, $\eta$ and $\eta_{m}$ are the efficiency of pump (0.85) and electric motor (0.70), respectively.

\subsubsection{Thermal resistance of pipes and heat-loss calculation}

The estimation of heat-losses from pipes is important while designing the district heating network. The proportion of heat-losses determine the supply and return water temperature as well as flows in the district heating network. In this study, a thermal resistance model is implemented for calculating distribution heatlosses and outlet water temperature from each pipe.

The thermal resistance depends on the composition material of pipe, ground surrounding the pipe and temperature difference. The thermal resistance of pipe's steel mantle is ignored as it's negligible compared to other resistances. The thermal resistance of insulation $\left(R_{i}\right)$ and ground $\left(R_{g}\right)$ is calculated considering thermal conductivity of respective materials [28]. Furthermore, the thermal resistance $\left(R_{h}\right)$ is due to heat 

resistances are defined as,

$$
\begin{gathered}
R_{i}=\frac{1}{2 \pi \lambda_{i}} * \ln \left(\frac{D_{m}}{D_{o}}\right) \\
R_{g}=\frac{1}{2 \pi \lambda_{g}} * \ln \left(\frac{2 H}{D_{m}}+\sqrt{\left(\frac{2 H}{D_{m}}\right)^{2}-1}\right) \\
R_{h}=\frac{1}{2 \pi \lambda_{g}} * \ln \left(\sqrt{\left(\frac{2 H}{S_{c}}\right)^{2}+1}\right)
\end{gathered}
$$

The thermal conductivity of PEX insulation foam $\left(\lambda_{i}\right)$ usually varies between $0.024-0.026 \mathrm{~W} / \mathrm{m}^{\circ} \mathrm{C}[29]$ and depends upon several factors such as, temperature, moisture and degradation of insulation material. The thermal conductivity $\left(\lambda_{i}\right)$ is calculated using following relation from experimental results in Ref. [30]. This relation considers variation in water temperature to get accurate results.

$$
\lambda_{i}=0.0196734+0.000080747303 * T_{\text {water }}
$$

The thermal conductivity of ground $\left(\lambda_{g}\right)$ is taken constant. The effective burial depth $(H)$ is the resistance between air and ground due to convective and radiation heat transfer [28, 31].

$$
H=S_{d}+0.0685 * \lambda_{g}
$$

$S_{d}$ is the depth of pipe from soil level, $S_{c}=L_{c}+D m . L_{c}$ is the distance between supply and return pipe and $D_{m}$ is the pipe diameter. The thermal resistance due to interaction between three sections, water-insulation ${ }_{120}\left(R_{w i}\right)$, ground-surroundings $\left(R_{g u}\right)$ and insulation-ground $\left(R_{i g}\right)$ is determined using following equations [28].

$$
\begin{gathered}
R_{w i}=\frac{1}{2 \pi \lambda_{i}} * \ln \left(\frac{1+\frac{D_{m}}{D_{o}}}{2}\right) \\
R_{g u}=\frac{1}{2 \pi \lambda_{g}} * \ln \left(\frac{4 H}{D_{m}+D_{g}}+\sqrt{\left.\left(\frac{4 H}{D_{m}+D_{g}}\right)^{2}-1\right)}\right. \\
R_{i g}=R_{i}+R_{g}-R_{w i}-R_{g u}
\end{gathered}
$$

These results are then scaled to get actual steady state heat-loss [28] using the factor $(\theta)$.

$$
\begin{gathered}
\theta=\left(R_{i}+R_{g}\right) \frac{\left(R_{i}+R_{g}\right)-\gamma R_{h}}{\left(R_{i}+R_{g}\right)^{2}-R_{h}^{2}} \\
\gamma_{\text {supply }}=\frac{\Delta T_{r}}{\Delta T_{s}}=\frac{T_{r p}-T_{u}}{T_{s p}-T_{u}}
\end{gathered}
$$




$$
\gamma_{\text {return }}=\frac{\Delta T_{s}}{\Delta T_{r}}=\frac{T_{s p}-T_{u}}{T_{r p}-T_{u}}
$$

$T_{u}$ is the soil temperature, $\gamma_{\text {supply }}$ for supply pipe, is the ratio between return water temperature $\left(\Delta T_{r}\right)$ and supply water temperature $\left(\Delta T_{s}\right)$. Moreover, $\gamma_{\text {return }}$ for return pipe, is the inverse of $\gamma_{\text {supply }}$. Combining all above equations provide the total heat transmission resistance $\left(R_{\text {total }}\right)$ and overall heat transfer coefficient ${ }_{125}(U)$.

$$
\begin{gathered}
R_{t o t a l}=R_{w i}+R_{g u}+R_{i g} \\
U=\frac{1}{R_{\text {total }}} \theta
\end{gathered}
$$

Finally, the heat-loss $\left(Q_{\text {loss }}\right)$ and outlet water temperature from each pipe $\left(T_{\text {outlet }}\right)$ [32] is calculated as,

$$
\begin{gathered}
Q_{\text {loss }}=U * l *\left(T_{\text {supply }}-T_{u}\right) \\
T_{\text {outlet }}=\left(T_{\text {inlet }}-T_{u}\right) \exp ^{-\frac{U . l}{C_{p} \cdot m}}+T_{u}
\end{gathered}
$$

The Eq. 23. represents the outlet water temperature from each pipe section is directly proportional to the mass flow-rate $(m)$ and inversely proportional to the length $(l)$ as well as overall heat transfer coefficient of the pipe $(U) . T_{\text {inlet }}$ is the inlet water temperature from the previous pipe and $T_{\text {outlet }}$ is the outlet water temperature to the next pipe.

\section{Case study: low temperature district heating intervention in Nottingham}

Nottingham is located in the eastern region of England known as East-midlands. It is the seventh largest metropolitan economy in the United Kingdom and ninth largest city having population of around 321,550. This city has the largest district heating network in entire UK, connecting approximately 4,900 domestic and commercial users [33] in the city centre. This $68 \mathrm{Km}$ of well-insulated district heating pipe network relies on heat from the waste-incinerator, which generates 442 - 476 GWh of heat annually and provides steam to the combined heat and power (CHP) plant. The pressurised hot-water from CHP plant enters the district heating network at a rated pressure and supply water temperature of 11 bar and $140^{\circ} \mathrm{C}$, respectively.

The heat-generation and distribution in Nottingham has very high amount of heat-losses. Though, the waste-incinerator generates 442 - 476 GWh of heat annually, only 144 GWh of heat is used for distribution. The seasonal variation of supply water temperature is between $85-120^{\circ} \mathrm{C}$. Ianakiev et al. [33] have discussed that almost $21 \%$ of heat is wasted during heat transmission from waste-incinerator to the CHP plant, and $36 \%$ during electricity generation at the CHP plant as flue-gases. The CHP plant makes both networks inter-related i.e. electricity and district heating network. However, if these losses are reduced, then more electricity can be generated. The current network operates with following priority: 
1. Burning of waste in waste-incinerator.

2. Electricity generation.

3. Heat for the heating network.

The district heating is significant to the city, especially with it's recent ambitious targets of achieving $20 \%$

150 already burns annual waste of around 170,000 tonnes and the district heating scheme offsets approximately 27,000 tonnes of $\mathrm{CO}_{2}$ emissions annually 33 .

A district heating network involves two sections, primary heating network and secondary heating network. The primary heating network in Nottingham has a CHP plant as heat source, which provides hot water which utilises return water pipe of the district heating network. It has anticipated that this will provide a gateway to Nottingham in efficiency improvement and extension of existing district heating network as well.

\section{Analysis and results}

This section uses LTDH intervention in Nottingham as a case-study and compares results of this study for four different operational scenarios. The analysis is divided into two parts. First, the significance of retrofitting of buildings is discussed using monitored weather in Section 4.2. Then, the hourly monitored operational data is discussed in Section 4.3.1 and the hydraulic imbalance in existing space-heating system inside the building is analysed. Subsequently, these hourly monitored data-sets are used as input for the hydraulic model and the hydraulic performance for planned LTDH network is evaluated in Sections 4.3 .2 and 4.3.3 respectively. Finally, results are compared for four different operational scenarios and recommendations for resolving hydraulic imbalance issue in LTDH network are described in Section 5

\subsection{Monitored weather data}

The weather data is hourly mean of multiple years data. This is done to smooth-out the effect of extreme events, otherwise weather data for an individual year can have sharp peaks. The monitored weather data contains hourly outdoor temperature, wind speed, wind direction, soil temperature and solar radiations data. This data is first converted into Energy-plus climate file (.epw) and then imported into IDA-ICE software, as discussed above in Section 2

It is observed in Fig. 2 that, the outside air temperature is rarely below $0^{\circ} \mathrm{C}$ and varies between 2 $10^{\circ} \mathrm{C}$ in winters and $15-25^{\circ} \mathrm{C}$ in summers. Moreover, Nottingham receives fairly significant amount of solar 

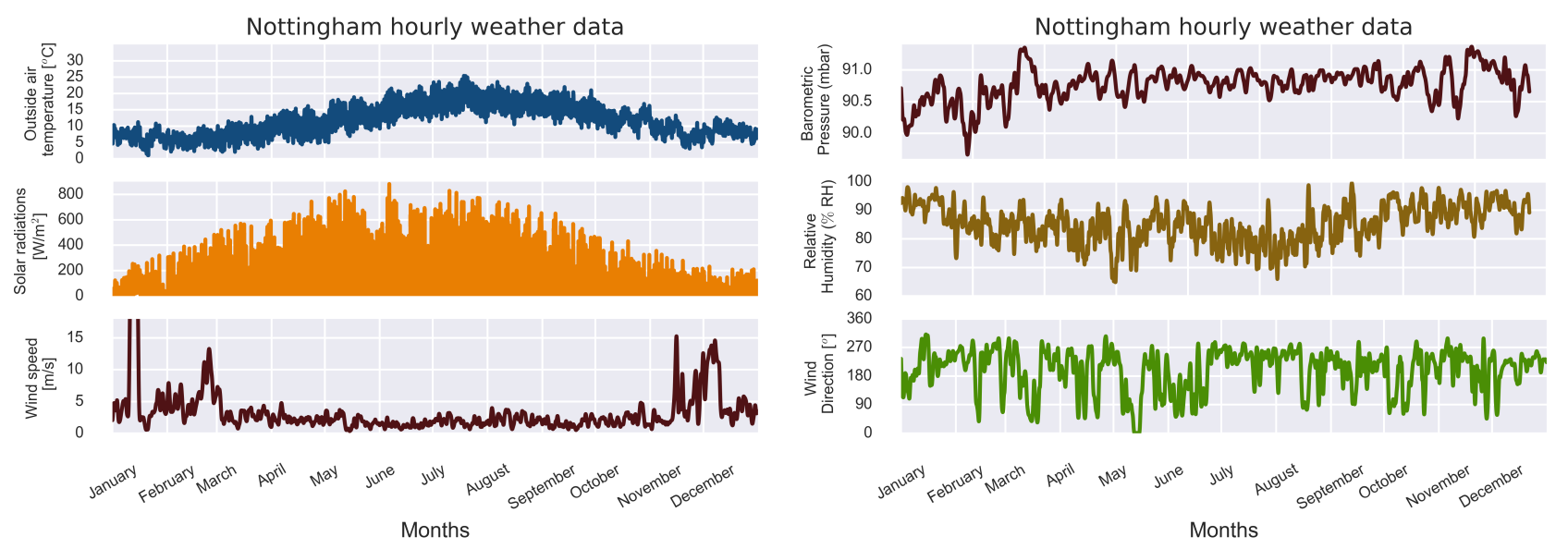

Figure 2: Hourly monitored weather data for Nottingham. This weather data is used for heat demand estimation. The heat demand in buildings depends upon outside weather conditions, therefore three years (2014-2016) of meteorological data is taken from the weather station located at $53^{\circ} 3^{\prime} 41.62^{\prime \prime} \mathrm{N}, 0^{\circ} 57^{\prime} 49.75^{\prime \prime} \mathrm{W}$.

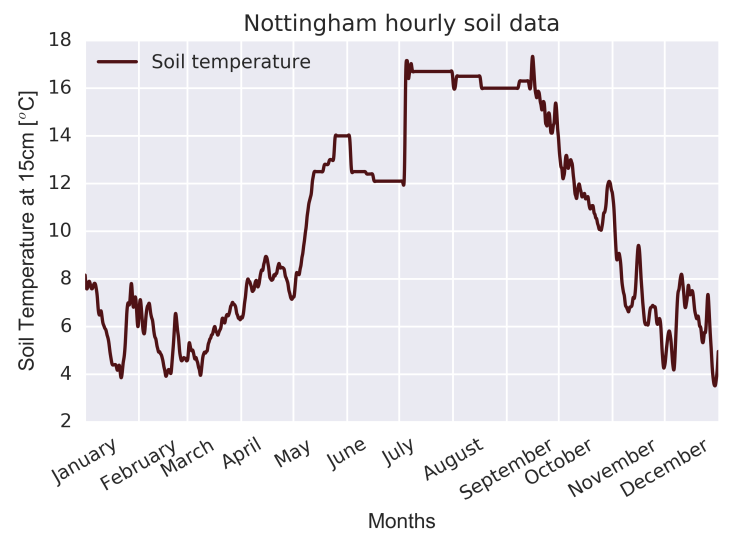

Figure 3: Hourly monitored soil temperature data of Nottingham, measured at $15 \mathrm{~cm}$ depth. This data is hourly mean of three years (2014-2016) of meteorological data and taken from the weather station located at $53^{\circ} 3^{\prime} 41.62^{\prime \prime} \mathrm{N}, 0^{\circ} 57^{\prime} 49.75^{\prime \prime} \mathrm{W}$. The soil temperature data is used for calculating outlet water temperature and heat-loss from district heating pipes.

radiations especially in months from April - September and the hourly solar radiations are up to $900 \mathrm{~W} / \mathrm{m}^{2}$. This elaborates the importance to consider solar radiations in heat demand calculations. Furthermore, the solar radiations and wind speed depict opposite trend to each other. The hourly wind speed is mostly smooth in summers and varies between $1-6 \mathrm{~m} / \mathrm{s}$. However, it fluctuates considerably from December to February, with the maximum wind gust speed in January. This is the period when there are wind storms in the UK.

The hourly soil temperature is important for outlet water temperature and heat-loss from district heating pipes calculations. Fig. 3 shows that, the soil temperature varies between $8-16^{\circ} \mathrm{C}$ in summers and $4-8^{\circ} \mathrm{C}$ in winters, respectively. All these hourly monitored data-sets are used as input for heat demand and hydraulic modelling simulations of the LTDH network. 

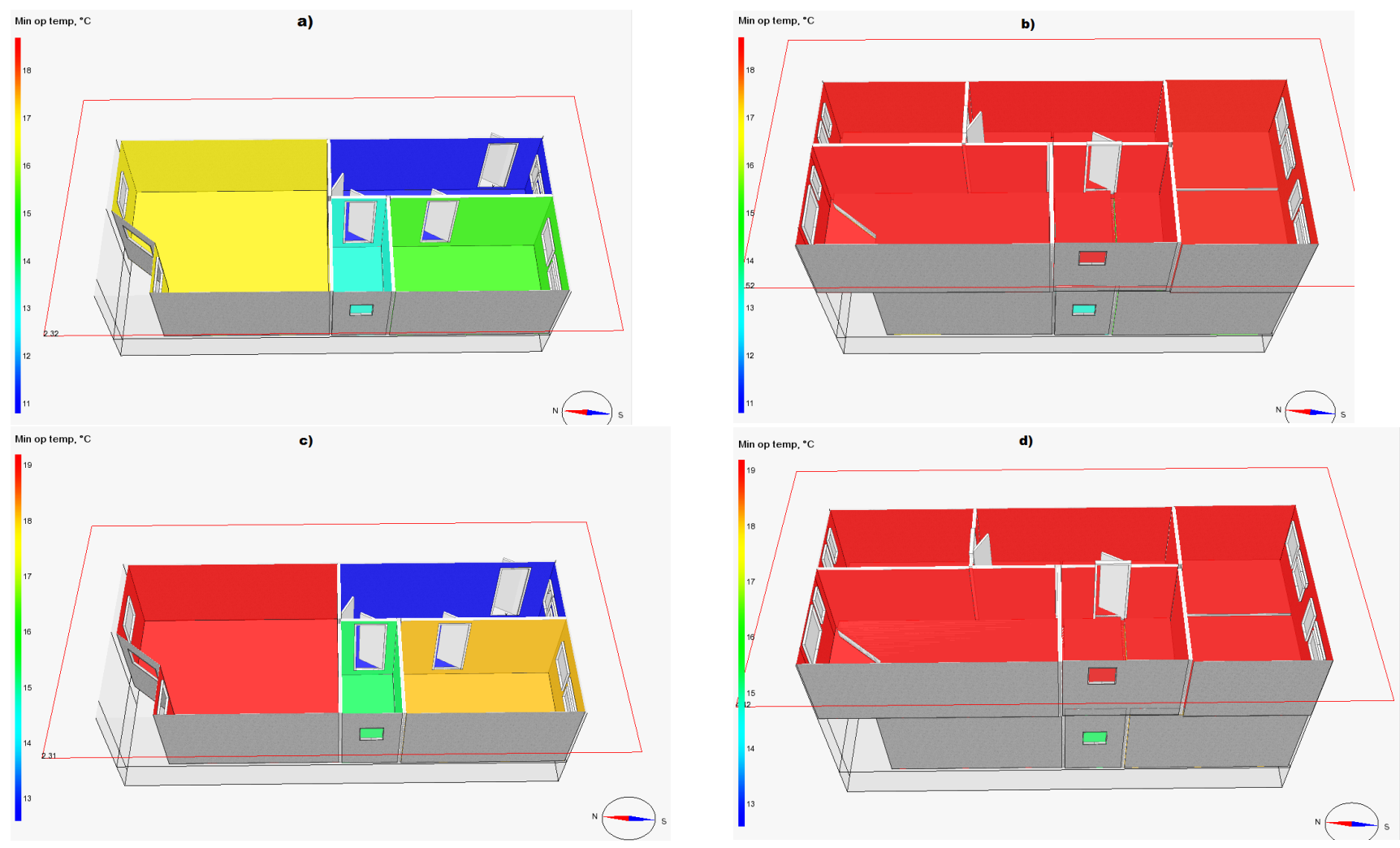

Figure 4: Simulation results from the IDA-ICE software. Figs.(a,b) show the minimum operative temperature before the retrofit and figs.(c,d) show minimum operative temperature after the retrofit.(For interpretation of the references to colour in this figure legend, the reader is referred to the web version of this article).

\subsection{Heat demand after retrofitting of buildings}

Improving the energy performance of existing buildings is a major corner-stone for moving towards low carbon economy, as 75 - 85\% of existing building stock in the UK will still be operational by the year 2050 [33]. Moreover, retrofitting of buildings is necessary for the implementation of LTDH. In REMOURBAN Project, 94 flats will be deep-retrofitted with the aim to increase the energy performance of existing buildings. These 94 flats are in four blocks, constructed from 1960's.

In this analysis, one of the building from REMOURBAN project is used and heat demand is calculated for both pre-retrofit and post-retrofit conditions. The U-value for the walls, roof, floor, windows and other building material information is taken from the survey, as these buildings are part of social community housing where no construction plans were available. The pre-retrofit building has raft-foundations and constructed 
with brick cavity walls, concrete floor slabs, single glazing windows and roof covered with concrete tiles. to $0.3,1.8$ and $0.123 \mathrm{~W} / \mathrm{m}^{2} \mathrm{~K}$, respectively. This post-retrofit condition is in accordance with the national standard for new building envelopes 'UK Building Regulation - Part L1B' [34. The deep-retrofitting has energy savings closer to the normal retrofitting practice and improved the U-value with the insulation of walls, floor and glazing, as shown in Table 1

The simulation results in Fig. 4 show that, the mean operative temperature for all zones is around $19^{\circ} \mathrm{C}$ at the minimum outdoor air temperatures with exception for the entrance region. The lower mean operative temperature at main entrance of the flat is due to the infiltration and opening of the entrance door according to the schedule. The retrofitting has improved the upper-limit of air infiltration from $0.6 \mathrm{ac} / \mathrm{hr}$ (air changes per hour) to 1.0 under 50 Pascal 35. It is calculated that, the major difference is noticed in the heat demand for the ground floor, where the mean operative temperature after the retrofit has increased from $17^{\circ}-19^{\circ} \mathrm{C}$.

The post-retrofit annual energy demand for each flat has been reduced from 23,897 to 11,253 KWh. This reduction of almost $52 \%$ is achieved by just improving windows glazing from single to double glazed, walls and roof insulation. These results for the reduction in annual heat demand obtained from IDA-ICE software are comparable to the real monitored heat consumption. The specific room minimum operative temperatures for different zones are shown in Fig. 4

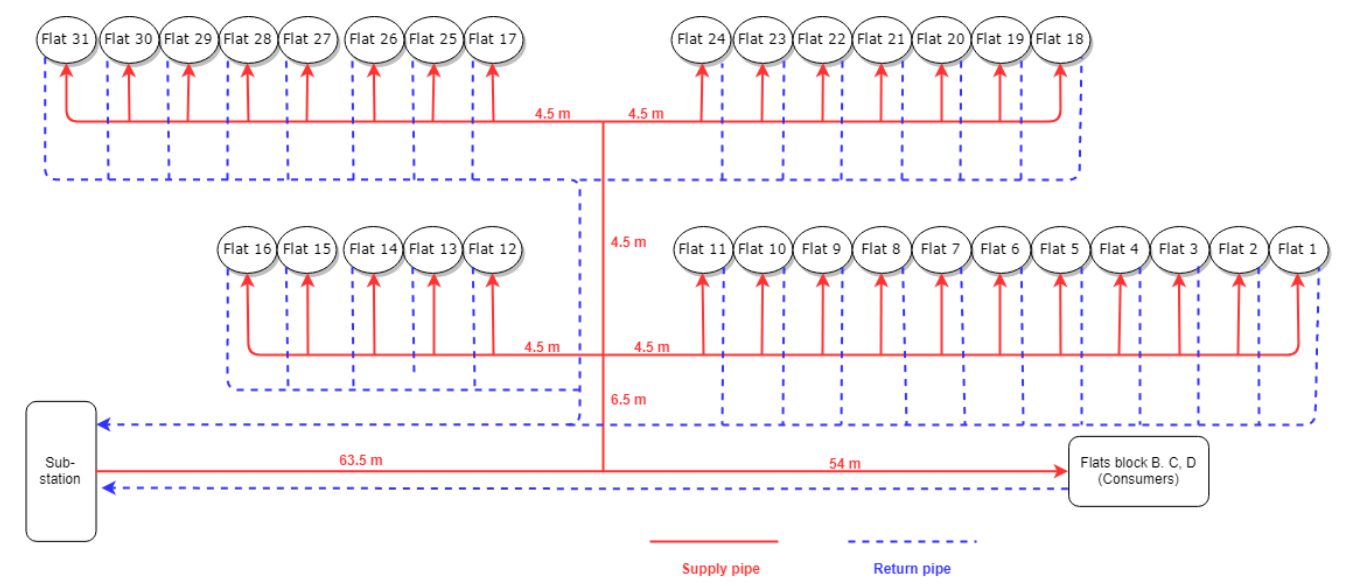

Figure 5: The main topology layout of the low temperature district heating network from REMOURBAN Project in Nottingham, UK.

\subsection{Hydraulic analysis}

The hydraulic balance of the space heating system is considered as a pre-condition for achieving high $\Delta \mathrm{t}$. The hydraulic balance in a well-functioning heating network is maintained when the water flow in entire heating network is balanced. A low temperature heating network is in hydraulic balance when the flow-rate and difference between the supply and return water temperature i.e. $\Delta \mathrm{t}$ is in accordance to the consumer heat consumption in the heating network [9]. The hydraulic imbalance issue leads to lower efficiency, low 
$\Delta \mathrm{t}$ and uneven distribution of heat in the heating network. This also leads to thermal comfort issues and over-heating in buildings due to excess heat, which make the residents to open windows. The heating network has optimal hydraulic performance when the energy consumption for fulfilling hydraulic head at consumers

The boiler based space-heating system in the UK buildings operate with constant flow-rate and the hydraulic balance is maintained by regulating supply water temperature according to the heat consumption. 


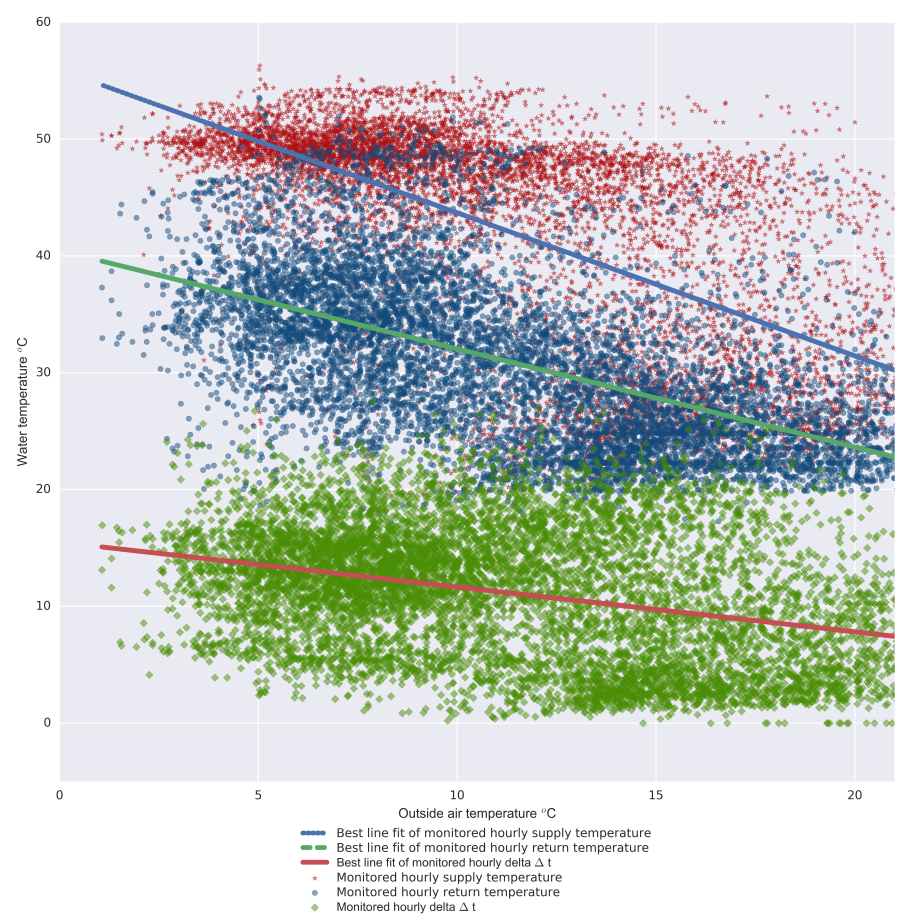

Figure 7: Real hourly monitored supply and return water temperature data of space-heating system from an existing boiler based building. The scatter plot presents the relationship between water temperature and outdoor air temperature. The best line fit of hourly monitored supply and return water temperature, depicts negative correlation between the water temperature and outside air temperature. This confirms the significance for regulation of return water temperature with respect to outside temperature for achieving high $\Delta$ t.(For interpretation of the references to colour in this figure legend, the reader is referred to the web version of this article).

This approach is helpful in achieving the hydraulic imbalance, but impacts the $\Delta t$ and overall efficiency of heating system. Nevertheless, the installation of TRVs on radiators somehow regulates the flow-rate with respect to indoor temperature, but the hourly monitored space-heating system data discussed below suggests that, the $\Delta$ t still remains low.

The heat demand, supply and return water temperature data from the existing boiler based building is monitored for understanding current operation of the space-heating system, before it's conversion to LTDH. Each flat in the building is installed with individual gas-boiler for space-heating and the indoor room temperature is controlled by TRVs on radiators. The schematic of space-heating system loop inside the flat is shown in Fig. 6 and the power capacity of installed hydronic radiator in Table 2

It is interesting to observe in Fig. 77, that the supply and return water temperature decreases with increase in outside air temperature. The $\Delta \mathrm{t}$ of space-heating system is highest when the outside temperature is at $0^{\circ} \mathrm{C}$ and lowest at around $23^{\circ} \mathrm{C}$, respectively. The best line fit of hourly monitored supply and return water temperature, depicts negative correlation between the water temperature and outside air temperature. Moreover, the slope of supply water temperature is steeper than the return water temperature. This methodology 
for the evaluation of hydraulic imbalance has been adopted from Zhang et al. [10, where the best line fit also depicts the negative correlation.

Furthermore, the supply water temperature remains relatively smooth whereas, the return water temperature fluctuates by more than $20^{\circ} \mathrm{C}$ for the same outdoor air temperature and consequently lowers the $\Delta t$. These variations in supply and return water temperature keeps the average $\Delta t$ to just 11 throughout the year. Even-though, the network has been designed and configured for the $\Delta t$ of 30 . This further confirms that, the supply water temperature decreases rapidly with increase in outside temperature, than the return water temperature. These trends can be observed from the scatter plot in Fig. 7.

It is concluded that, the regulation of return water temperature with respect to outside temperature is more significant, than the supply water temperature for achieving high $\Delta \mathrm{t}$. Moreover, these variations in return water temperature compared with supply water temperature at the same outdoor temperature, is due to the hydraulic imbalance in space-heating system. This is assumed due to lack of thermal comfort complaints reported by occupants during the heating season and the space-heating system operates at constant flow-rate.

275 This hydraulic imbalance issue can be explained due to the over-sizing of room radiators and other control equipment inside the building.

The following scenarios use this hourly monitored space-heating system operational data and weather data from Section 4.1 for hydraulic calculations in the LTDH network. The control valve settings are kept same in all scenarios, as it provides the reasonable comparison among results.

\subsubsection{Scenario 1 and 3 - constant supply water temperature}

The supply water temperature in both scenarios 1 and 3 is kept constant from the sub-station at $60^{\circ} \mathrm{C}$. The flow-rate is constant in scenario 1, whereas it varies in scenario 3 with respect to the outdoor temperature using variable speed pumps and weather compensation control at the sub-station.

It is observed that, the energy consumption in scenario 3 reduces from $964 \mathrm{KWh}$ to $360 \mathrm{KWh}$ with variable 285 flow-rate in the LTDH network. This reduction of almost $63 \%$ in scenario 3 by flow-rate variation suggests that variable speed pumps are more energy efficient, especially at partial heat consumption conditions. The variable speed pumps regulate the supply flow-rate from substation and more energy efficient. The head-loss at each flat in scenario 3 is lower compared to that in scenario 1, but it shows similar trend in both scenarios. The energy consumption and head-loss comparison in different operational scenarios is graphically shown below in Figs. 8,9 and 10

The heat-loss from district heating pipes in the LTDH network is almost same in both scenarios. This represents the strong dependence of heat-loss from pipes on supply water temperature, than the flow-rate. Even-though, the seasonal variation increases the soil temperature, but the heat-loss from district heating pipes remains pretty same throughout the year. Moreover, the flow-rate and pumping power are comparatively higher in summer. This is due to low $\Delta \mathrm{t}$ and shown in Fig. 11. The overall heat-losses in the LTDH network reduces from $62 \%$ to $47 \%$ in scenario 3 . This reduction by almost $14 \%$ in scenario 3 suggests that the variable speed pump reduces the heat-losses but up to a certain limit. These results are compared graphically 


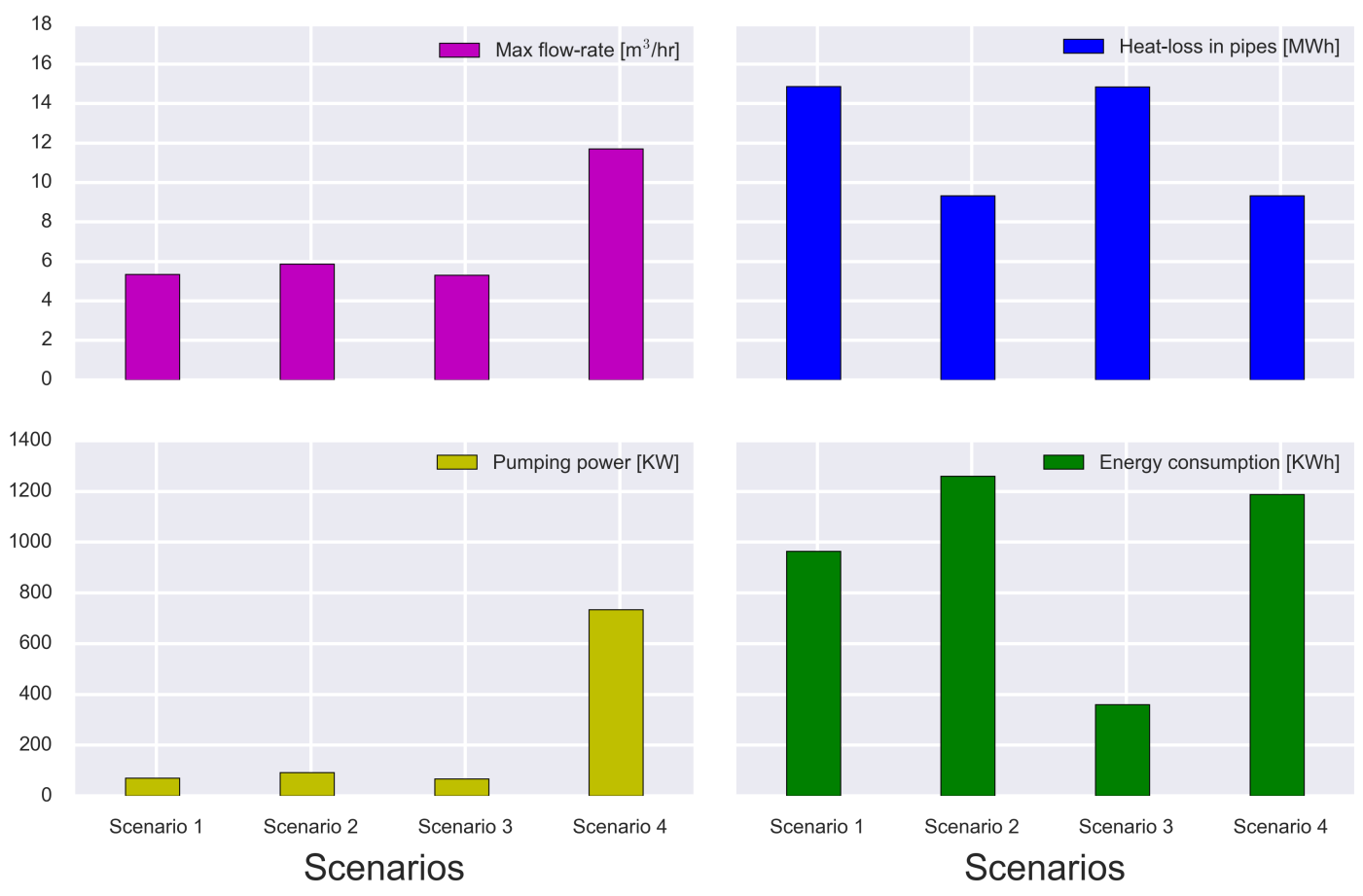

Figure 8: Comparison of results between different operational scenarios. First row represents maximum flow-rate from the plant room and heat-loss from district heating pipes in the ground during heat transmission. The second row represents pumping power and energy consumption of the LTDH network.

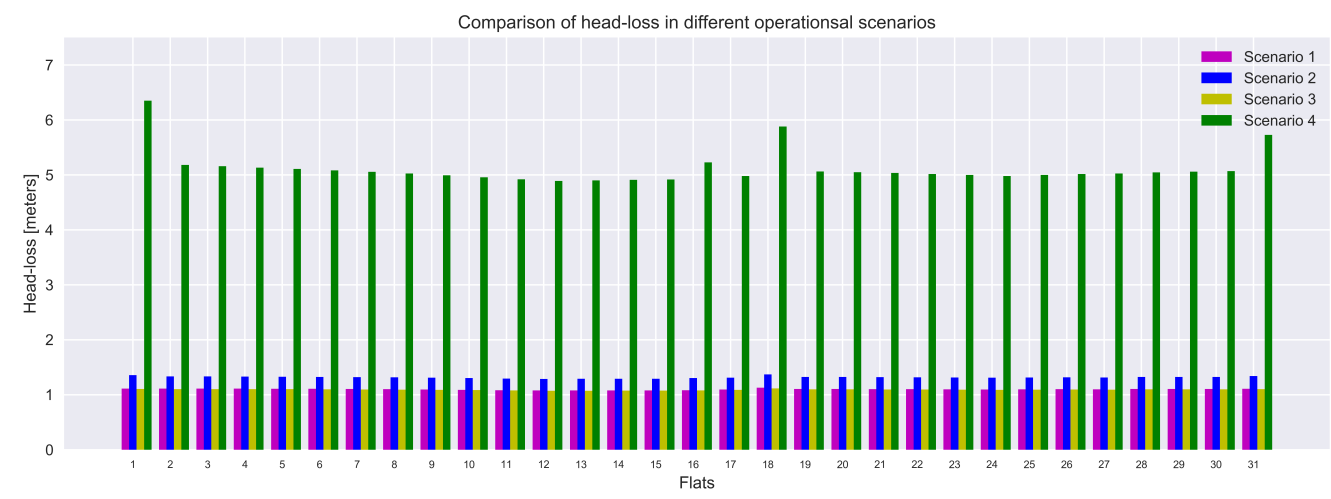

Figure 9: Head-loss comparison to each flat in different operational scenarios.

among scenarios 1 and 3 in Fig. 12 and further elaborated in Table 3

\subsubsection{Scenario 2 and 4 - variable supply water temperature}

The scenario 2 and 4 apply when the supply water temperature varies with respect to outdoor temperature from the sub-station. The flow-rate is constant in scenario 2, whereas it's variable in scenario 4 using variable speed pumps in the LTDH network. 


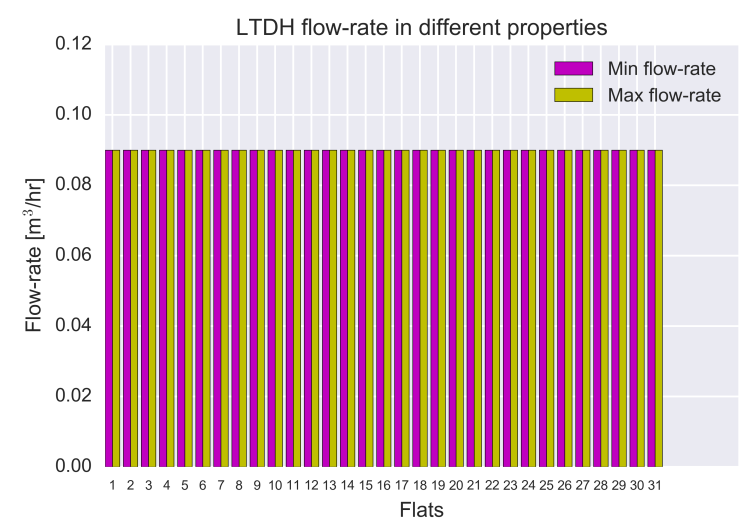

Figure 10: Figure represents the maximum and minimum flow-rate restricted to each flat using flow-rate control valves in the LTDH network.

It is found that the supply water temperature variation increases energy consumption considerably compared to scenario 1. The energy consumption increases from 964 to $1261 \mathrm{KWh}$, respectively. This $29 \%$ increase of energy consumption in scenario 2 and $22 \%$ increase in scenario 4 can be understood, as the flowrate increases with reduction in supply water temperature from the sub-station. However, the head-loss in scenario 2 is comparable to scenario 1, but the pumping power increases by $32 \%$. The flow-rate and head-loss in scenario 4 are both significantly higher compared with scenario 1 . These energy consumption and head-loss results are shown in Figs. 8,9
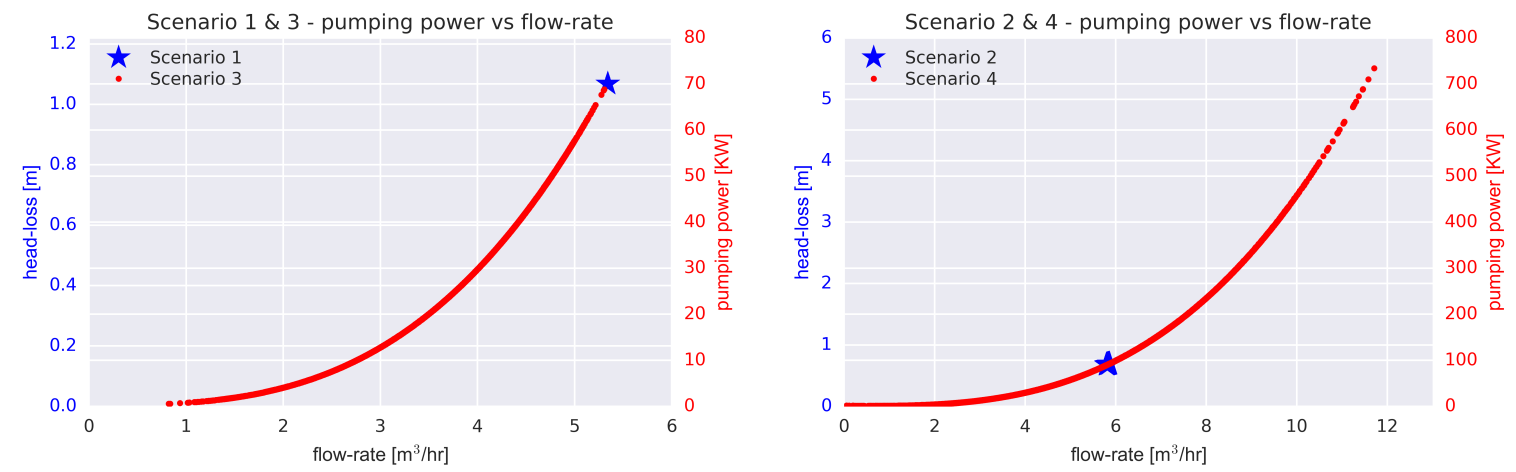

Figure 11: Pumping power with respect to flow-rate and head-loss for different operational scenarios. Left figure compares result for scenarios 1 and 3, whereas right figure compares result for scenarios 2 and 4 .

It is observed that the heat-loss from district heating pipes in both scenarios reduces by $37 \%$, and the heat-loss in scenario 4 is even lower than scenario 3. Nevertheless, the flow-rate and pumping power are comparatively higher in scenario 4. These results are shown in Figs. 11 and 12 It is concluded that, reducing supply water temperature is more effective compared with flow-rate variations for reduction in heat-losses in the LTDH network. The overall heat-losses in LTDH network in scenarios 2 and 4 are reduced 

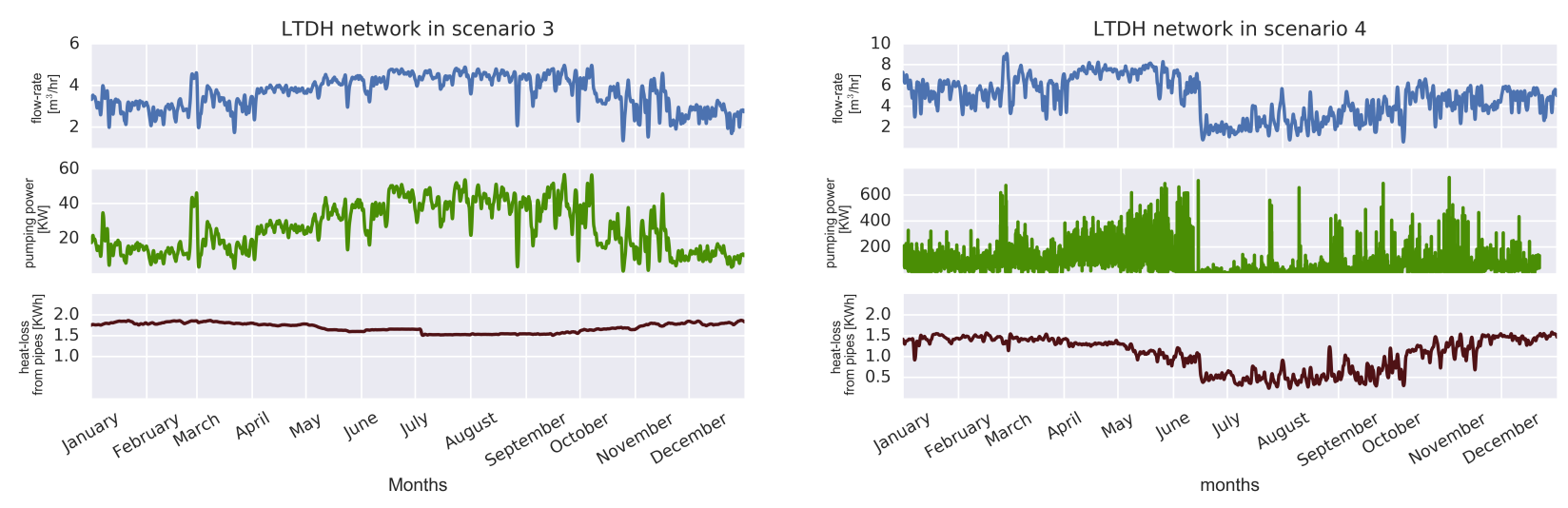

Figure 12: Comparison between the operational scenario 3 and 4. First and second row represents hourly flow-rate and pumping power from the plant room, whereas the third row represents hourly heat-loss from district heating pipes in the ground during heat transmission.

to just $9 \%$ and $11 \%$, respectively. These heat-losses are minimal compared with other scenarios. These results, along with comparison are further elaborated in Table 3

\section{Discussion and recommendations}

The district heating networks in the UK commonly operate with high supply water temperature and constant flow-rate, as fixed speed pumping is still preferred. This leads to high heat-losses in the district heating network. The efficiency of these heating networks can be improved significantly if the $\Delta \mathrm{t}$ is improved.

This study concludes that variable speed pumping with constant supply water temperature from the sub-station has the lowest energy consumption and should be adopted for the new LTDH networks, as explained in scenario 3. Whereas, the heat-losses in existing district heating networks which operate at constant flow-rate can be reduced significantly, if the supply water temperature is regulated according to the outside temperature. This can be done using weather compensation control at the sub-station and elaborated in scenario 2. Furthermore, lowering of supply water temperature significantly decreases heat-losses in the LTDH network and provides the opportunity to utilise renewable heat sources and other low-grade waste heat sources. But, it should be realised that, this will increase energy consumption in the LTDH network. The Fig. 8 shows the comparison between other operational scenarios.

The case study in Section 4.3.1 illustrates the hydraulic imbalance issue for a typical space-heating system in the UK, where only control valves are installed in the supply pipes and no balancing valves or flow-limiters are installed on the return pipes. It can be presumed that the absence of these valves creates the hydraulic imbalance, which leads to the low $\Delta t$ and excessive heat-losses across the LTDH network. This is usually complimented with high supply water temperature from the sub-station, which leads to high heat-losses and 


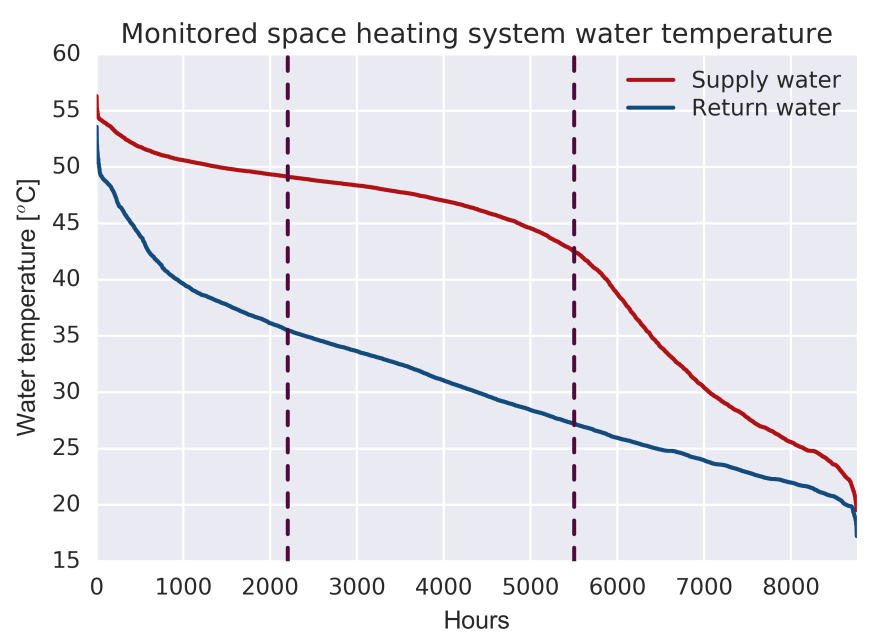

Figure 13: Load duration curve of the monitored supply and return water temperature of space-heating system.

\subsection{Load duration curve}

The district heating networks in the UK require high pumping power capacities due to low $\Delta \mathrm{t}$ across the network. It is often thought that the entire heating network is prone to this problem. However, this analysis shows that it is hydraulic imbalance problem which leads to high return water temperatures in the district heating network.

The load duration curve in Fig. 13 further elaborates that, the $\Delta \mathrm{t}$ is mostly above 20 between 2100 5500 hours in a year and suddenly reduces afterward. Moreover, the return water temperature remains very high for 2100 hours. This can be presumed due to the hydraulic imbalance in late spring and early autumn season. The hydraulic imbalance issue can be attributed to the incorrect installation of heating equipment or the absence of flow-limiter valves on return water pipe. This explains that space-heating systems can operate until $43^{\circ} \mathrm{C}$, but the return water temperature must be restricted in-between $35-28^{\circ} \mathrm{C}$ for achieving high $\Delta \mathrm{t}$ throughout the year.

\subsection{Recommendations}

The hydraulic imbalance in the heating network is usually due to the incorrect estimation of the heat consumption, over-sized control valves, over-sized or incorrect adjusted pumps, problems with equipment commissioning, the absence of flow-limiter and control equipment [9]. It is recommended that following measures might improve the hydraulic imbalance issue in the UK heating networks.

1. Implementation of balancing valves and flow-limiters on return water pipes in the heating network.

2. Installation of pressure independent thermostatic radiator valves (TRVs) in high-rise buildings.

3. The district heating pipes shall not be over-sized intentionally.

4. Installation of hydronic radiators in top bottom opposite end (TBOE) configuration instead of bottom bottom opposite end (BBOE) configuration. 
This study shows that, TRVs alone are unable to maintain the hydraulic balance in existing space-heating system in buildings. Moreover, importance should be given to the pipe sizes in the LTDH network. These

360 pumping power and energy consumption. The hydraulic balance in the space-heating systems might improve, if pressure independent TRVs are used on radiators. This is considered as ideal solution for space-heating systems especially in high-rise buildings. Otherwise, another solution can be using pre-setting function of TRVs on radiators, along with balancing valves and differential pressure controller in the district heating network, as discussed by Zhang et al. [10]. The pre-setting function restricts the amount of water flowing through the radiator.

Furthermore, it is believed that the $\Delta \mathrm{t}$ might increase significantly, if LTDH radiators are connected in top bottom opposite end (TBOE) configuration, instead of bottom bottom opposite end (BBOE). In the UK, hydronic radiators are commonly connected in the bottom, bottom, opposite end (BBOE) scheme according to the BS-3521 standard [36], which lays down condition for connecting radiators in the heating network. BBOE connections are used in old-fashioned heating networks, where the flow-rate and supply water temperatures are kept high [37, 38. Even-though, the current focus is on reducing supply water temperatures and improving $\Delta \mathrm{t}$, but hydronic radiators are still being installed in the BBOE scheme.

It is recommended that, the optimisation of heating networks, especially space-heating system loop inside buildings is required in the UK. This can be achieved by dynamic analysis of the heating network, development of weather based auto-regression model for correct heat demand prediction in extreme events 39. If the proposed recommendations are applied in the LTDH networks, then considerable energy consumption savings are expect to be achieved. This will consequently have a positive environmental impact as well.

\section{Conclusion}

This paper presents a model which investigates the hydraulic performance and calculates flow-rate, heatlosses, pumping power and energy consumption of the LTDH network. This model is used to demonstrate the hydraulic performance in four operational different scenarios for a planned LTDH network in Nottingham, UK. The results are calculated using actual network parameters, monitored weather data and space-heating system operational data from an existing building. The implication of reducing supply water temperature on hydraulic performance of the LTDH network is analysed in each scenario and the optimum scenario is found. Following are the main conclusions drawn from this research.

1. The weather data shows retrofitting of building has significant impact on the energy consumption. The hourly monitored weather time-series data shows that, Nottingham receives a fairly high amount of solar radiations and the outside air temperature rarely goes below $0^{\circ} \mathrm{C}$. This explains the significance of solar radiations in heat demand calculations. Moreover, deep-retrofitting of existing building has great impact on the energy performance of building. The building used as case study in this shows that 
deep-retrofitting has reduced the energy consumption by more than $50 \%$ and increased the operative temperature by $2^{\circ} \mathrm{C}$.

2. This study demonstrates that the conversion of existing buildings to LTDH network is technically possible, as the supply water temperatures are already lower than $60^{\circ} \mathrm{C}$. However, high return water temperature due to the hydraulic imbalance in existing boiler based space-heating systems leads to high heat-losses. This needs to be resolved before their conversion to LTDH network.

3. The hourly monitored data from the space-heating system shows that the regulation of return water temperature with respect to outside temperature is more significant, than the supply water temperature for achieving high $\Delta \mathrm{t}$. Moreover, the $\Delta \mathrm{t}$ decreases with increase in outside temperature and the average $\Delta \mathrm{t}$ throughout the year is just 11. Even-though, the heating network has been designed and configured for the $\Delta \mathrm{t}$ of 30 .

4. While comparing different operational scenarios it is found that the energy consumption of the LTDH network is lowest in scenario 3, when the flow-rate is variable and supply water temperature is kept constant from the sub-station. The variation in supply water temperature reduces the heat-losses in the LTDH network, but increases energy consumption of the LTDH network. Therefore, fluctuating renewable heat sources and low-grade waste heat will impact the hydraulic performance of the network.

5. The heat-losses in existing district heating networks which are currently operating at constant flow-rate and supply water temperature can be reduced significantly, if the supply water temperature is regulated using weather compensation control at the sub-station. Nevertheless, this will increase the pumping power and energy consumption in these networks.

\section{Acknowledgments}

The authors gratefully acknowledge the financial support from the REMOURBAN project supported by the EU Horizon 2020 research and innovation programme under grant agreement No 646511. The sponsor had no involvement in the design or delivery of this paper. Moreover, Ms. Saba Ferdous from CRUK Manchester for helpful suggestions during this research.

\section{References}

[1] U. Persson, B. Möller, S. Werner, Heat roadmap europe: Identifying strategic heat synergy regions, Energy Policy 74 (2014) 663 - 681. doi:10.1016/j.enpol.2014.07.015.

[2] A. David, B. Mathiesen, H. Averfalk, S. Werner, H. Lund, Heat roadmap europe: Large-scale electric heat pumps in district heating systems, Energies 10 (4). doi:10.3390/en10040578

[3] A. Ashfaq, Z. H. Kamali, M. H. Agha, H. Arshid, Heat coupling of the pan-European vs. regional 口 electrical grid with excess renewable energy, Energy 122 (2017) 363 - 377. doi:10.1016/j.energy. 2017.01 .084 
[4] S. R. Jones, M. Gillot, R. Boukhanouf, G. Walker, Project scenic: smart controlled energy networks integrated communties, Tech. rep., University of Nottingham (2017).

[5] A. Ashfaq, Z. H. Kamali, M. H. Agha, H. Arshid, Heat coupling of the pan-european vs. regional electrical grid with excess renewable energy, Energy 122 (2017) 363 - 377. doi:10.1016/j . energy.2017.01.084.

[6] P. Woods, J. Overgaard, Historical development of district heating and characteristics of a modern district heating system, in: R. Wiltshire (Ed.), Advanced District Heating and Cooling (DHC) Systems, Woodhead Publishing Series in Energy, Woodhead Publishing, Oxford, 2016, pp. 3 - 15. doi:10.1016/ B978-1-78242-374-4.00001-X

[7] H. Lund, S. Werner, R. Wiltshire, S. Svendsen, J. E. Thorsen, F. Hvelplund, B. V. Mathiesen, 4th generation district heating (4gdh): Integrating smart thermal grids into future sustainable energy systems, Energy 68 (2014) 1 - 11. doi:10.1016/j.energy.2014.02.089.

[8] L. Zhang, J. Xia, J. E. Thorsen, O. Gudmundsson, H. Li, S. Svendsen, Method for achieving hydraulic balance in typical chinese building heating systems by managing differential pressure and flow, Building Simulation 10 (1) (2017) 51-63. doi:10.1007/s12273-016-0307-2

[9] H. Boysen, J. E. Thorsen, Hydraulic balance in a district heating system, Tech. rep., Danfoss DIstrict Heating (2007).

[10] L. Zhang, O. Gudmundsson, J. E. Thorsen, H. Li, X. Li, S. Svendsen, Method for reducing excess heat supply experienced in typical chinese district heating systems by achieving hydraulic balance and improving indoor air temperature control at the building level, Energy 107 (2016) 431 - 442. doi: $10.1016 / j$.energy.2016.03.138

[11] X. Yang, H. Li, S. Svendsen, Modelling and multi-scenario analysis for electric heat tracing system combined with low temperature district heating for domestic hot water supply, Building Simulation 9 (2) (2016) 141-151. doi:10.1007/s12273-015-0261-4.

[12] X. Yang, H. Li, S. Svendsen, Evaluations of different domestic hot water preparing methods with ultralow-temperature district heating, Energy 109 (2016) 248 - 259. doi:10.1016/j.energy.2016.04.109.

[13] D. S. Østergaard, S. Svendsen, Case study of low-temperature heating in an existing single-family house - a test of methods for simulation of heating system temperatures, Energy and Buildings 126 (Supplement C) (2016) 535 - 544. doi:10.1016/j.enbuild.2016.05.042.

[14] M. Tunzi, D. S. Østergaard, S. Svendsen, R. Boukhanouf, E. Cooper, Method to investigate and plan the application of low temperature district heating to existing hydraulic radiator systems in existing buildings, Energy 113 (2016) 413 - 421. doi:10.1016/j.energy.2016.07.033 
[15] L. Zhang, O. Gudmundsson, J. E. Thorsen, H. Li, X. Li, S. Svendsen, Method for reducing excess heat supply experienced in typical chinese district heating systems by achieving hydraulic balance and improving indoor air temperature control at the building level, Energy 107 (2016) 431 - 442. doi: $10.1016 / j \cdot$ energy $\cdot 2016.03 .138$

[16] L. Zhang, J. Xia, J. E. Thorsen, O. Gudmundsson, H. Li, S. Svendsen, Technical, economic and environmental investigation of using district heating to prepare domestic hot water in chinese multi-storey buildings, Energy 116, Part 1 (2016) 281 - 292. doi:10.1016/j.energy.2016.09.019.

[17] N. Deng, R. Cai, Y. Gao, Z. Zhou, G. He, D. Liu, A. Zhang, A minlp model of optimal scheduling for a district heating and cooling system: A case study of an energy station in tianjin, Energydoi: $10.1016 / j \cdot$ energy.2017.10.130

[18] A. Yan, J. Zhao, Q. An, Y. Zhao, H. Li, Y. J. Huang, Hydraulic performance of a new district heating systems with distributed variable speed pumps, Applied Energy 112 (2013) 876 - 885. doi:10.1016/j. apenergy.2013.06.031

[19] H. Wang, L. Duanmu, X. Li, R. Lahdelma, Optimizing the district heating primary network from the perspective of economic-specific pressure loss, Energies 10 (8). doi:10.3390/en10081095.

[20] EQUA, User manual: IDA indoor climate and energy, version 4.5, Tech. rep., EQUA Simulation AB (February 2013).

[21] DS/EN 15265, Danish standard energy performance of buildings - calculation of energy needs for space heating and cooling using dynamic methods - general criteria and validation procedures, denmark, Tech. rep. (2007).

[22] EQUA, Validation of IDA indoor climate and energy 4.0 with respect to CEN standards EN 15255-2007 and EN 15265-2007, Tech. rep., EQUA Simulation AB (2010).

[23] Danish standard, DS 469-heating and cooling systems in buildings, denmark, Tech. rep. (2013).

[24] S. Frederiksen, S. Werner, District Heating and Cooling, Studentlitteratur AB, 2013.

[25] CIBSE, Heat networks: Code of practice for the uk - raising standards for heat supply, Tech. rep., Chartered Institution of Building Services Engineers (CIBSE) and Association for Decentralised Energy (ADE) (2015).

[26] Y. A. Çengel, Heat \& Mass Transfer: A Practical Approach, McGraw-Hill Education Pvt Limited, 2007.

[27] R. H. T. Yunus A. Çengel, John M. Cimbala, Fluid Mechanics [Si Units], McGraw-Hill Education Pvt Limited. 
[28] H. Palsson, Analysis of numerical methods for simulating temperature dynamics in district heating pipes, University of Iceland, Faculty of Engineering, 1997, pp. 1-20.

[29] R. Lund, S. Mohammadi, Choice of insulation standard for pipe networks in 4th generation district heating systems, Applied Thermal Engineering 98 (2016) 256 - 264. doi:10.1016/j .applthermaleng. 2015.12 .015

[30] I. Gabrielaitiene, B. Bøhm, B. Sunden, Evaluation of approaches for modeling temperature wave q propagation in district heating pipelines, Heat Transfer Engineering 29 (1) (2008) 45-56. doi: 10.1080/01457630701677130.

[31] B. Bøhm, Experimental determination of heat losses from buried district heating pipes in normal operation, Heat Transfer Engineering Vol. 22 (2001) pp. 41-51.

[32] X. Liu, J. Wu, N. Jenkins, A. Bagdanavicius, Combined analysis of electricity and heat networks, Applied Energy 162 (Supplement C) (2016) 1238 - 1250. doi:10.1016/j.apenergy.2015.01.102

[33] A. Ianakiev, J. M. Cui, S. Garbett, A. Filer, Innovative system for delievery of low temperature district heating.

[34] H. Government, The building regulation 2010 - part 11b conservation of fuel and power in existing dwellings, Tech. rep. (2010).

[35] J. M. Cui, A. Ianakiev, M. . García-Fuentes, To examine appropriate deep-retrofit practice using simulation results in an eu-funded urban regeneration project, Energy Procedia 105 (Supplement C) (2017) 2549 - 2556, 8th International Conference on Applied Energy, ICAE2016, 8-11 October 2016, Beijing, China. doi:10.1016/j.egypro.2017.03.733

[36] BS-3528, Specification for convection type space heater operating with steam or hot water. (equivalent to is0 3147 , is0 3148 , is0 3150$)$, Tech. rep. (1977).

[37] D. A. McINTYRE, Output of radiators at reduced flow rate, Tech. rep., Electricity Council Research Centre, Capenhurst, Chester (1986).

[38] I. Ward, Domestic radiators: Performance at lower mass flow rates and lower temperature differentials than those specified in standard performance tests, SAGE Publications Ltd STM- Building Services Engineering Research and Technology 12 (3) (1991) 87 - 94. doi:10.1177/014362449101200301.

[39] M. Dahl, A. Brun, G. B. Andresen, Using ensemble weather predictions in district heating operation and load forecasting, Applied Energy 193 (Supplement C) (2017) 455 - 465. doi:10.1016/j .apenergy. 2017.02 .066 


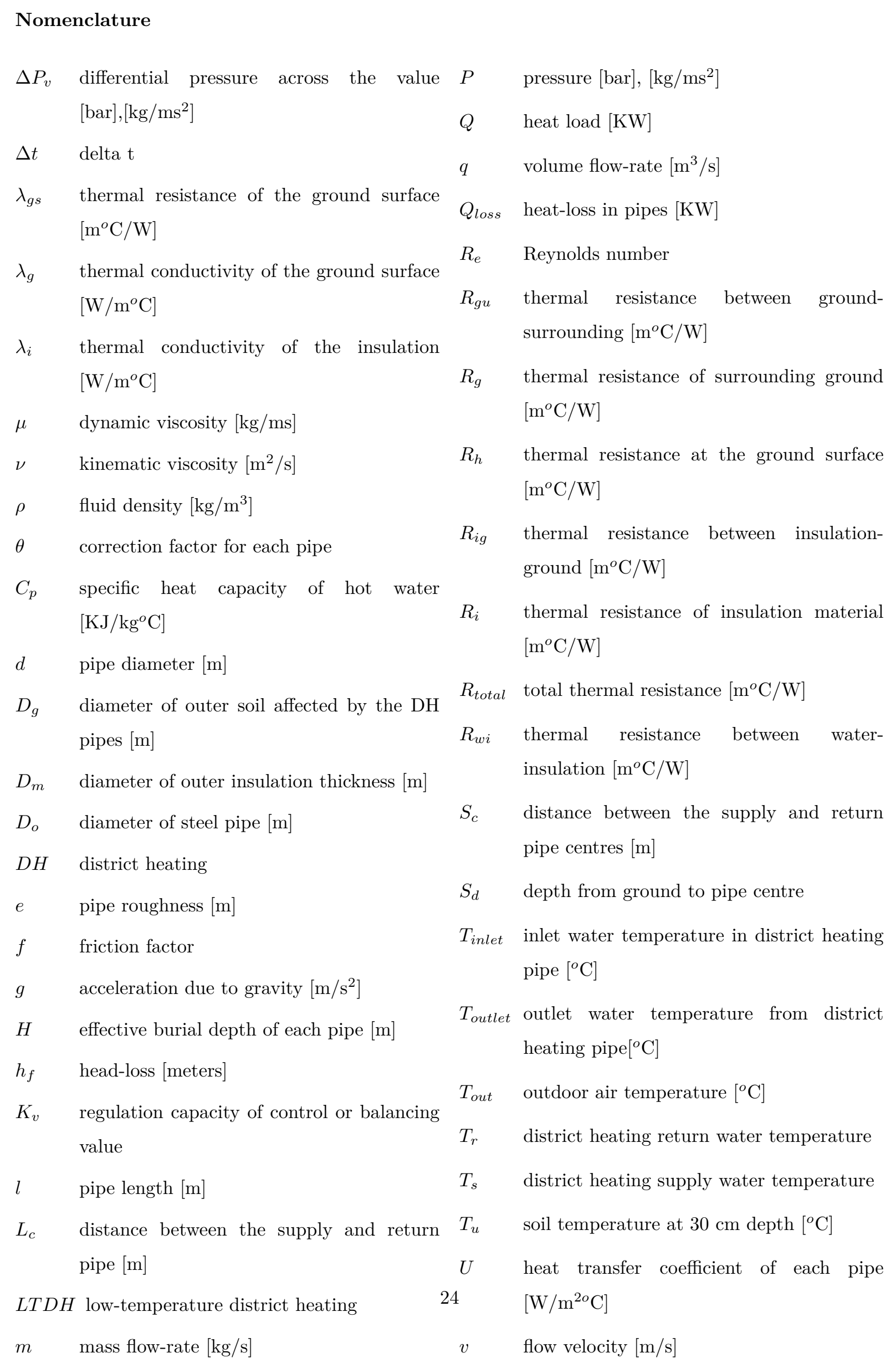


Table 1: Main material properties of flat, before and after the deep-retrofit.

\begin{tabular}{|l|l|l|}
\hline Component & Before retrofit & After retrofit \\
\hline Wall & U- value $\left(\mathrm{W} / \mathrm{m}^{2} \mathrm{~K}\right)$ & $\mathrm{U}$ - value $\left(\mathrm{W} / \mathrm{m}^{2} \mathrm{~K}\right)$ \\
\hline Glazing & 2.1 & 0.3 \\
\hline Roof & 2.727 & 1.8 \\
\hline Floor & 0.346 & 0.123 \\
\hline Overhang & 2.128 & 2.128 \\
\hline Heat demand $(\mathrm{KWh})$ & 2.128 & 2.128 \\
\hline
\end{tabular}

Table 2: Radiators installed in the flat from REOMRBAN project.

\begin{tabular}{|l|l|l|l|l|}
\hline No. & Room & Radiator size & Radiator type & Power output $(\mathrm{W})$ \\
\hline 1 & Hallway & $1100 \times 600$ & Single panel, single convector & 1,100 \\
2 & Lounge & $1600 \times 600$ & Double panel, double convector & 2,845 \\
3 & Bathroom & $500 \times 600$ & Double panel, double convector & 889 \\
4 & Kitchen & $400 \times 600$ & Double panel, double convector & 711 \\
5 & Bedroom - 1 & $1400 \times 600$ & Single panel, single convector & 1,400 \\
6 & Bedroom - 2 & $1000 \times 600$ & Single panel, single convector & 1,000 \\
7 & Bedroom - 3 & $400 \times 600$ & Double panel, double convector & 711 \\
\hline
\end{tabular}

Table 3: Comparison between different operational scenarios.

\begin{tabular}{|l|l|l|l|l|}
\hline & Scenario 1 & Scenario 2 & Scenario 3 & Scenario 4 \\
\hline Flow-rate & constant & constant & variable & variable \\
Supply water temperature & constant & variable & constant & variable \\
\hline Maximum flow-rate from plant room $\left(\mathrm{m}^{3} / \mathrm{hr}\right)$ & 5.34 & 5.87 & 5.31 & 11.71 \\
Minimum flow-rate from plant room $\left(\mathrm{m}^{3} / \mathrm{hr}\right)$ & 5.34 & 5.87 & 0.82 & 0.05 \\
Heat-loss from district heating pipes $(\mathrm{MWh})$ & 14.86 & 9.34 & 14.85 & 9.34 \\
Maximum pumping power $(\mathrm{KW})$ & 70 & 92.68 & 68.82 & 734.07 \\
Energy consumption (KWh) & 964 & 1261 & 360 & 1189 \\
Overall heat-losses in LTDH network (MWh) & $62.25 \%$ & $9.6 \%$ & $47.66 \%$ & $11.13 \%$ \\
\hline
\end{tabular}

